\title{
AWARENESS OF DIABETES MELLITUS AMONG GENERAL PUBLIC IN SHAH ALAM, MALAYSIA: A CROSS-SECTIONAL STUDY
}

\author{
MUHAMMAD QAMAR*, RAIZ RASYID MOHAMED IQUBAL, SOHAIL AHMAD, FAIZ AHMED SHAIKH, \\ NAHLAH ELKUDSSIAH ISMAIL
}

Department of Clinical Pharmacy, Faculty of Pharmacy, MAHSA University, Bandar Saujana Putra, 42610 Jenjarom, Kuala Langat, Selangor, Malaysia. Email: mqamar18@gmail.com

Received: 15 February 2017, Revised and Accepted: 26 May 2017

ABSTRACT

Objective: Despite the improved healthcare and frequent community-ridden educational awareness campaigns, the prevalence of diabetes is enormously increasing and $50 \%$ of the Malaysian adults with diabetes are still unaware of their disease status. Therefore, this study aimed to assess the awareness of diabetes mellitus (DM) among the general public of Shah Alam, Malaysia.

Methods: A cross-sectional study was carried out in five urban areas of Shah Alam. A total of 350 participants were conveniently recruited using a pre-validated questionnaire. The questionnaire comprised two main parts, including the sociodemographic characteristics of the respondents and a 24-item Diabetes Knowledge Questionnaire. The data were analyzed by Statistical Package for the Social Science ${ }^{\circledR}$ using descriptive and inferential statistics.

Results: The overall mean ( \pm standard deviation) score of DM knowledge of participants was $11.11 \pm 6.09$. Among 350 respondents, more than half claimed that medication is more important than lifestyle modification in DM management. 81.7\% did not know about the frequent urination and thirst are signs of DM. $82.3 \%$ had a misconception that diabetes is caused by failure of the kidneys to keep sugar out of the urine. The knowledge score was statistically significant difference across the categories of level of education, monthly income, occupations, and family history of diabetes.

Conclusion: Majority of enrolled respondents possessed moderate level of awareness and misconceptions regarding diabetes and its management. Hence, there is a need for collective efforts toward improving the level of awareness through community awareness campaigns, to improve the selfmanagement of DM.

Keywords: Awareness, Knowledge, Diabetes mellitus, Shah Alam, Malaysia.

(C) 2017 The Authors. Published by Innovare Academic Sciences Pvt Ltd. This is an open access article under the CC BY license (http://creativecommons. org/licenses/by/4. 0/) DOI: http://dx.doi.org/10.22159/ajpcr.2017.v10i9.17747

\section{INTRODUCTION}

Diabetes mellitus (DM) has become one of the most significant noncommunicable and overall rampant illness, affecting members of both the wealthy and non-wealthy [1,2]. Approximately, 170 million individuals suffer from the disease universally and if this trend is allowed to endure, the number is expected to double by the year 2030 [3]. Health-care professionals and scientists are currently more focused to study about diabetes and its management since the disease is rising fast, despite needing ample time to be established [4]. The escalation in financial burden will highlight the complications and problem of the disease since it has a great rate of recurrence and incidence worldwide, especially in a non-developed nation [5]. It was demonstrated that $80 \%$ of the population lives in low- and moderate-earning states and about 382 million people have diabetes [6]. Allocation of resources for the health sector and the public, highlighting the significance of lifestyle, and initialization of action required to halt the growing occurrence of diabetes are crucial factors that make way for predicting the present and future problem of the disease [7].

Diabetes situation in Malaysia is also worrying as about 3.5 million or $17.5 \%$ of its citizen aged more than 18 years and above had diabetes. Despite the extensive utilization of health-care resources in frequent community-ridden educational awareness campaigns, the prevalence of diabetes is drastically increasing. According to the World Health Organization, Malaysia is expected to carry a total figure of 2.48 million people with diabetes during 2030 which is $164 \%$ greater compared to 0.94 million in 2000 [8]. The occurrence of the disease stated to be $0.65 \%$ and $2-4 \%$ in the year 1960 and 1980 , respectively, but rise rapidly to $8-12 \%$ by the year 1990 [9]. Based on the Third National
Health and Morbidity Survey (NHMS III), it shows that Malaysia already surpassed the estimated prevalence of diabetes aimed for the year 2025 compared to the present as predicted by the International Diabetes Federation [10]. This chronic progressive disease if not tackled in its early stages may eventually lead to serious health concerns and in return might attribute to morbidity and mortality. Long-term injury, organ dysfunction, and failures mainly the kidneys, eyes, heart, nerves, and blood vessels reported in diabetes [11]. To avoid the adverse consequences of DM, public awareness should be an integral part of health promotion campaign. There is limited literature available about awareness of general public regarding DM. Therefore, this study aimed to assess the awareness of DM among the general public in urban areas of Shah Alam, Malaysia.

\section{METHODS}

\section{Study design and population}

A cross-sectional study was carried out in Shah Alam, Selangor Darul Ehsan using pre-validated questionnaire. The recommended sample size with $5 \%$ margin of error, $95 \%$ confidence level with $50 \%$ response distribution, was 350 respondents as calculated by online Raosoft Software ${ }^{\circledR}$. Post-oral consent, this study recruited the participants from the general public in five urban areas of Shah Alam (Section 7, Section 9, Section 11, Section 13, and Section 19).

\section{Data collection}

This study questionnaire was distributed at places of common interest (shopping malls, educational institutes, fast foods, and households). Participants were requested to answer the questionnaire on spot and were subsequently collected after completion. A pre-validated, self- 
administered, and close-ended questionnaire was distributed to the respondents by convenience sampling. The duration required for the data collection of this study was three months from February to April 2016

\section{Inclusion and exclusion criteria}

All of the respondents who were of at least or above 18 years of age, regardless of their gender, ethnicity, socioeconomic status, and voluntarily willing to participate were included in our study. Only healthy individuals were included in this study and people suspected with any cognitive and/or psychiatric impairment were excluded from our study. Written or verbal consent was obtained before handing over the self-administered questionnaire to the respondent as per respondent's choice. The names of the respondents or any personal identification details were not asked intentionally. Furthermore, respondents who were unable to read English were provided with an alternative Malay version of the questionnaire.

\section{Diabetes knowledge questionnaire (DKQ)}

The DKQ-24, originally developed for Mexican-American adults with Type 2 diabetes, was adapted by Garcia and associates for the diabetes self-management project at Gateway Community Health Center [12]. The instrument comprises 24 items assessing the knowledge of diabetes among the general public. The questionnaire comprised two parts. Part I includes sociodemographic data (gender, age group, ethnicity, level of education, occupation, monthly income, family history of diabetes, preferred source of information, and social history) and Part II was about the diabetic knowledge. The DKQ-24 was divided into four global areas or domains based on types of information regarding Type 1 diabetes: Treatment of diabetes and related effects, long-term complications of diabetes, causes of diabetes, and hyperglycemia/ hypoglycemia. Each question comprised with the option "yes," "no," and "I don't know" that requires respondents to put a tick on the applicable column. Each correct answer was given "1" mark while "0" mark was given for the wrong and don't know answer. The DKQ-24 was translated from English into Malay by a native bilingual translator and then back translated by a different native bilingual translation specialist and checked for accuracy, clarity, and content equivalence by conducting forward and back translations to verify translation equivalence.

\section{Ethical consideration}

Ethical approval was obtained from the Institutional Review Board of Research Management Centre (RMC), MAHSA University (No. EA/Pharm/1205-2016). The individual participation was voluntary and verbal consent was acquired from each respondent. Confidentiality and anonymity of all participants were maintained as no names were mentioned in the questionnaires.

\section{Statistical analysis}

The extracted data from completed questionnaires were analyzed using Statistical Package for the Social Sciences ${ }^{\circledR}$. A system of point allocation was incorporated where one point was given to correct response and zero (none) was given to wrong or don't know response. The total maximum score for the diabetic knowledge was 24. Knowledge scores were categorized into three levels indicated by poor (0-8), moderate (9-16), and good (17-24) level of knowledge. Data were expressed as descriptive statistics such as mean, frequency, and percentage. Independent t-test and one-way ANOVA were used to find out the differences of knowledge score across various sociodemographic categories. The level of statistical significance was set at $\mathrm{p}<0.05$.

\section{RESULTS}

\section{Sociodemographic characteristics of the respondents}

Out of 400,350 respondents gave their consent to participate and return the questionnaire to the principle investigator, therefore, the response rate of this study was $87.5 \%$ (350/400) that surpassed the good index of response rate. It can be observed that the most respondents who participated in this study were within the age group of 27-35 (23.7\%) and the majority of them were female (57.1\%) and Malay (45.7\%). Highest level of education among the enrolled respondents was tertiary education (61.1\%) followed by secondary education (34.6\%). Over $40.6 \%$ of these participants were employed in private sector, followed by government sector (38\%). $43.7 \%$ of respondents had a monthly income of more than 3000 Ringgit Malaysia per month. In addition, a positive family history of DM and being diabetic were reported by $38.9 \%$ and $22.9 \%$, respectively (Table 1 )

\section{Source of information}

Internet, in addition to friends and relatives, represented foremost preferred sources of information on DM $(31.4 \%$ and $20.9 \%$, respectively), whereas medical staff represented the lowest source of information (3.4\%). The further details of respondents' sources of DM information in Shah Alam city are illustrated in Fig. 1.

\section{Diabetes knowledge of general public in region of Shah Alam}

The mean ( \pm standard deviation) score of correct answers on the DKQ was $11.11 \pm 6.09$, with a range from 0 to 21 and a median score of 11 , suggesting that the enrolled respondents possessed moderate level of knowledge. The correct response distribution of respondents is shown in Table 2. The items receiving more correct responses were, the usual cause of diabetes is a lack of effective insulin in the body, in untreated diabetes the amount of sugar in the blood usually increases, and diabetes can cause loss of feelings in hands, fingers, and feet by majority of the respondents: $75.1 \%, 74.9 \%$, and $72.6 \%$, respectively. Besides that, more than $50 \%$ reported medication is more important

Table 1: Sociodemographic data of respondents $(n=350)$

\begin{tabular}{|c|c|}
\hline Demographics & n (\%) \\
\hline \multicolumn{2}{|l|}{ Gender } \\
\hline Male & $150(42.9)$ \\
\hline Female & $200(57.1)$ \\
\hline \multicolumn{2}{|l|}{ Age (years) } \\
\hline $18-26$ & $82(23.4)$ \\
\hline $27-35$ & $83(23.7)$ \\
\hline $36-44$ & $78(22.3)$ \\
\hline $45-53$ & $72(20.6)$ \\
\hline $54-65$ & $35(10.0)$ \\
\hline \multicolumn{2}{|l|}{ Ethnicity } \\
\hline Malay & $160(45.7)$ \\
\hline Chinese & $83(23.7)$ \\
\hline Indian & $100(28.6)$ \\
\hline Others & $7(2.0)$ \\
\hline \multicolumn{2}{|l|}{ Level of education } \\
\hline None & $8(2.3)$ \\
\hline Primary & $7(2.0)$ \\
\hline Secondary & $121(34.6)$ \\
\hline Tertiary & $214(61.1)$ \\
\hline \multicolumn{2}{|l|}{ Occupation } \\
\hline Unemployed & $44(12.6)$ \\
\hline Self-employment & $31(8.9)$ \\
\hline Private & $142(40.6)$ \\
\hline Government & $133(38.0)$ \\
\hline \multicolumn{2}{|l|}{ Occupation } \\
\hline No income & $44(12.6)$ \\
\hline$<$ RM 1500 & $7(2.0)$ \\
\hline RM 1500-RM 1999 & $52(14.9)$ \\
\hline RM 2000-RM 2499 & $55(15.7)$ \\
\hline RM 2500-RM 2999 & $39(11.1)$ \\
\hline$>$ RM 3000 & $153(43.7)$ \\
\hline \multicolumn{2}{|c|}{ Family history of diabetes } \\
\hline Yes & $136(38.9)$ \\
\hline No & $214(61.1)$ \\
\hline \multicolumn{2}{|l|}{ Diabetic } \\
\hline Yes & $80(22.9)$ \\
\hline No & $270(77.1)$ \\
\hline \multicolumn{2}{|l|}{ If, yes } \\
\hline Type I & 20 (5.7) \\
\hline Type II & $60(17.1)$ \\
\hline
\end{tabular}


Table 2: Correct responses regarding general knowledge of DM

\begin{tabular}{|c|c|c|}
\hline S. No. & General knowledge of DM & n (\%) \\
\hline 1 & Eating too much sugar and other sweet foods are a cause of diabetes & $73(20.9)$ \\
\hline 2 & The usual cause of diabetes is lack of effective insulin in the body & $263(75.1)$ \\
\hline 3 & Diabetes is caused by failure of the kidneys to keep sugar out of the urine & $62(17.7)$ \\
\hline 4 & Kidneys produce insulin & $149(42.6)$ \\
\hline 5 & In untreated diabetes, the amount of sugar in the blood usually increases & $262(74.9)$ \\
\hline 6 & If I am diabetic, my children have higher chance of being diabetic & $249(71.1)$ \\
\hline 7 & Diabetes can be cured & $147(42.0)$ \\
\hline 9 & The best way to check my diabetes is by testing my urine & $84(24.0)$ \\
\hline 10 & Regular exercise will increase the need for insulin or other diabetic medication & $102(29.1)$ \\
\hline 11 & There are two main types of diabetes: Type 1 (insulin-dependent) and Type 2 (non-insulin-dependent) & $218(62.3)$ \\
\hline 12 & An insulin reaction is caused by too much food & $80(22.9)$ \\
\hline 13 & Medication is more important than diet and exercise to control my diabetes & $191(54.6)$ \\
\hline 14 & Diabetes often causes poor circulation & $221(63.1)$ \\
\hline 15 & Cuts and abrasions on diabetes heal more slowly & $221(63.1)$ \\
\hline 16 & Diabetics should take extra care when cutting their toenails & $248(70.9)$ \\
\hline 19 & Diabetes can damage my kidneys & $252(72.0)$ \\
\hline 20 & Diabetes can cause loss of feeling in my hands, fingers, and feet & $254(72.6)$ \\
\hline 21 & Shaking and sweating are signs of high blood sugar & $91(26.0)$ \\
\hline 22 & Frequent urination and thirst are signs of low blood sugar & $64(18.3)$ \\
\hline 23 & Tight elastic hose or socks are not bad for diabetes & $104(29.7)$ \\
\hline 24 & A diabetic diet consist mostly of specials foods & $66(18.9)$ \\
\hline
\end{tabular}

DM: Diabetes mellitus

Table 3: Level of diabetes knowledge

\begin{tabular}{lll}
\hline Knowledge category & Score & n (\%) \\
\hline Poor & $(0-8)$ & $112(32.0)$ \\
Moderate & $(9-16)$ & $146(41.7)$ \\
Good & $(17-24)$ & $92(26.3)$ \\
\hline
\end{tabular}

than diet and exercise to control DM. The questions least frequently answered correctly were "frequent urination and thirst are signs of low blood sugar" (18.3\%), followed by "Diabetes is caused by failure of the kidneys to keep sugar out of the urine" (17.7\%), and "a person with diabetes should cleanse a cut with iodine and alcohol (4\%)." The categorization based on score of knowledge of DM is revealed in Table 3. Based on the findings of inferential statistics (Table 4), significant differences were observed between DM knowledge score across gender $(\mathrm{p}<0.003)$, age $(\mathrm{p}<0.001)$, ethnicity $(\mathrm{p}=0.036)$, level of education $(p<0.001)$, occupation $(p<0.001)$, monthly income $(p<0.001)$, family history of diabetes $(\mathrm{p}<0.005)$, source of information $(\mathrm{p}<0.005)$, and being diabetic $(\mathrm{p}<0.001)$ categories.

\section{DISCUSSION}

This study indicated that the knowledge of DM among the general public was moderate level of awareness and misconceptions regarding diabetes and its management. The outcomes of this study consistent to the study conducted in Thailand, where it stated that the awareness of DM among the general public was found to be moderate [13]. On the contrary, the studies conducted in Kuala Lumpur, Klang, and Kelantan in Malaysia indicated that the knowledge of diabetes was found to be adequate and reasonably good [14-16]. In the current study, the moderate score was may be due to several factors. The active engagement in health education and promotion may be helpful to improve the awareness of DM at individuals as well community level among Malaysians.

The present study reported the alarming prevalence $(22.9 \% ; 5.7 \%$ Type I, 17.1\% Type II) of diabetes in the enrolled participants from the general public. The high prevalence was in accordance to the reported prevalence of NHMS 2015, and the future cautions issued by the Ministry of Health, Malaysia [17]. In addition, NHMS (2015) also stated

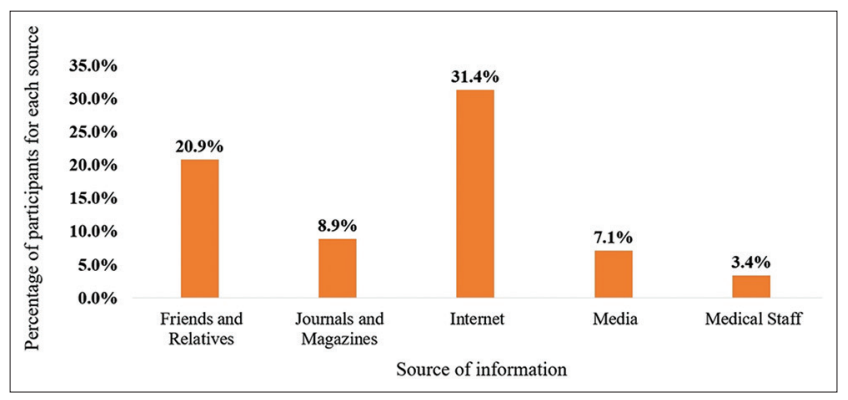

Fig. 1: Participants' sources of information about diabetes mellitus

that uncontrolled diabetes was due to the unhealthy lifestyle and eating imbalanced diet, as also suggested by Arafat et al. [18] that public who consume non-healthy diet are at higher risk for developing Type II DM. This may be due to lack of awareness and public health education.

Similar to finding of the present study, previous studies also reported the higher prevalence of diabetes among females. Our study also showed that diabetes is more prevalent in female that was in concurrence with the results of other studies [19-21].

There were a numerous number of sources of information were identified from where the respondents obtained information on diabetes. Based on the findings, the preference sources of information related to DM were through the internet and friends and relatives. These outcomes were similar to the study conducted in Kuala Lumpur by Qamar et al., in which most of the participants suggested internet, friends, and relatives as preferred source of DM awareness [14]. There are many articles and medical information available online from numerous websites which can be accessed easily through smartphones, computers, and laptops [22]. Moreover, the least preferred source of the DM awareness in the study population was medical staffs as found in Kuala Lumpur and Saudi Arabia based studies [14,23]. The underlined reason for this may be the lack of time of medical staffs for patient education [14].

More than $70 \%$ of the respondents aware that the usual cause of diabetes is ineffective insulin in the body resulting in increase level of 
Table 4: Comparison of knowledge score across sociodemographic categories $(n=350)$

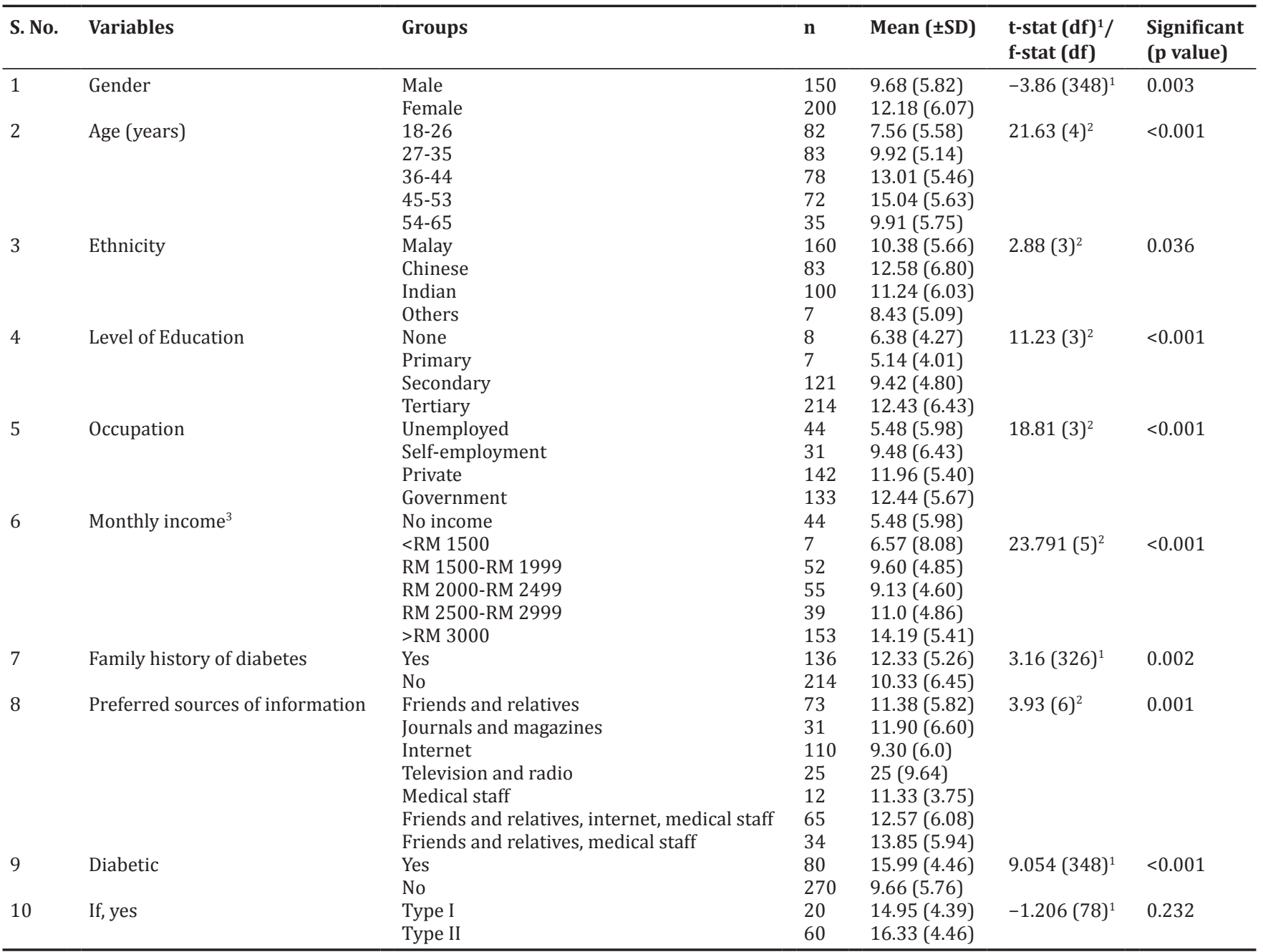

${ }^{1}$ The difference of mean total knowledge score was assessed using independent t-test, ${ }^{2}$ the difference of mean total knowledge score was assessed using one-way ANOVA, ${ }^{3}$ one Malaysia Ringgit (RM) $=0.23$ USD

sugar in the blood. This finding was similar to the studies conducted in Kuala Lumpur and Negeri Sembilan, respectively [14,24]. Most of the respondents also believed that eating too much sugar and other sweet foods are a cause of diabetes. Increase in sugar intake (more calories) may lead to obesity: Risk factor for DM. This might be due to the respondents believing that if someone avoids sugar, they will not have diabetes since most of them have little knowledge regarding carbohydrates and they believe sugar (table sugar) is a contributing factor of diabetes [25]. Despite the fact that the majority of our enrolled participants had moderate awareness, various false beliefs were also observed. The respondents had a misunderstanding that "diabetes is caused by failure of kidneys to keep sugar out of the urine" $(82.3 \%)$, followed by "frequent urination and thirst are signs of low blood sugar $(81.7 \%)$ ), "the best way to check diabetes is by testing urine" (75.5\%), and "diabetes can be cured" (58\%). Besides, they believed that tight elastic hose or socks are not bad for diabetics. All of the misconceptions were due to the lack of appropriate DM awareness as suggested by Qamar et al., Mohieldein et al., and Wee et al. [14,22,23]. It is vital to emphasize the fact that diabetes cannot be cured, but can only be managed. Individuals may not take the right action when it comes to complications of diabetes if they have misunderstandings about the disease [24].

Interestingly, there was high awareness and better understanding of DM among female and Chinese participants in their respective category. This result was similar to the study conducted by Sagaran and
Srinivasan and Murata et al. $[15,26]$. However, contradict the findings of a Rahman et al. and Soltanian et al. $[27,28]$ because both studies reported female participants as less aware of diabetes than males. The possible reason behind more female awareness was the difference in culture, health seeking behavior, and different literacy rate.

Furthermore, we observed that our elder participants scored significantly higher than the young participants, respondents with higher socioeconomic status, higher level of education, and family history of diabetes scored higher than respondents belonging to lowincome socioeconomic status, less level of education, and without family history of diabetes. These results are congruent with the results of previous studies conducted in Kelantan, Saudi Arabia, Ethiopia, and Vietnam, respectively [15-17,21,29-31]. Besides, respondents working in government sector slightly scored higher than private employees. Entrepreneurs along with government and private workers have a superior education background and exposure to educational resources [32]. Respondents with a source of information from friends and relatives along with medical staff showed greater understanding of diabetes compared to other sources of information. This may be because friends and relatives may have family members with diabetes or have acquired information from various sources, thus they convey the accurate information to the respondents. Comparatively with another study conducted by Strauss et al. [33] reported that health-care provider fared as the best source of information associated with good diabetes knowledge. 
We recommend the adaptation of collaborative care where physicians, pharmacists, and nurses should play their role in providing diabetes education to the society. Empowering the people by providing them ample education and targeting at least one member of each family to have adequate information about self-medication/diabetes can help to reduce the burden of health-care services.

One implication of the current study findings is that, despite moderate knowledge of DM, education could play a critical role in optimizing the self-management of DM. Future research should be focus to identify the ways to increase the public awareness and rectify their misconceptions of DM and its management. The present study has some limitations that need to be highlighted. First, the study used a convenience sample and recruited the people from selected urban areas of Shah Alam. Second, the design of the study was cross-sectional, the findings may not represent cause and effect relationship and result cannot be generalized. However, the present study lays the foundation for the future research and practice to improve the overall management of DM.

\section{CONCLUSION}

This study has shown that majority of the study respondents had moderate awareness regarding DM and there is a lack of understanding in certain areas. As the knowledge is considered to be the utmost defense in combating against DM; hence, the abrupt actions need to be taken to counteract these misconceptions. Subsequent development in awareness, attitudes, and skills will lead to superior control of diabetes and is widely accepted as a crucial part of complete diabetes management can be achieved through diabetes communication and education.

\section{ACKNOWLEDGMENTS}

The authors wish to thank the general public for participating in this study.

\section{REFERENCES}

1. Abegunde DO, Mathers CD, Adam T, Ortegon M, Strong K. The burden and costs of chronic diseases in low-income and middle-income countries. Lancet 2007;370:1929-38.

2. Hjelm K, Mufunda E, Nambozi G, Kemp J. Preparing nurses to face the pandemic of diabetes mellitus: A literature review. J Adv Nurs 2003;41(5):424-34.

3. Wild S, Roglic G, Green A, Sicree R, King H. Global prevalence of diabetes: Estimates for the year 2000 and projections for 2030. Diabetes Care 2004;27(5):1047-53.

4. Zimmet PZ. Diabetes epidemiology as a tool to trigger diabetes research and care. Diabetologia 1999;42(5):499-518.

5. Hoque MA, Islam MS, Khan MA, Ahasan HN. Knowledge of diabetic complications in a diabetic population. J Med 2009;10:90-3

6. Guariguata L, Whiting DR, Hambleton I, Beagley J, Linnenkamp U, Shaw JE. Global estimates of diabetes prevalence for 2013 and projections for 2035. Diabetes Res Clin Pract 2014;103(2):137-49.

7. Shaw JE, Sicree RA, Zimmet PZ. Global estimates of the prevalence of diabetes for 2010 and 2030. Diabetes Res Clin Pract 2010;87(1):4-14.

8. Mafauzy M. Diabetes mellitus in Malaysia. Med J Malaysia 2006;61(4):397-8.

9. Mustaffa BE. Diabetes epidemic in Malaysia. Med J Malaysia 2004;59(3):295-6.

10. Letchuman GR, Wan Nazaimoon WM, Wan Mohamad WB, Chandran LR, Tee GH, Jamaiyah $\mathrm{H}$, et al. Prevalence of diabetes in the Malaysian national health morbidity survey III 2006. Med J Malaysia 2010;65(3):180-6

11. Thabit MF. Awareness regarding diabetes mellitus and its' complications in Type 2 diabetic patients. Al Kindy Coll Med J 2013;9:25-8.

12. Garcia AA, Villagomez ET, Brown SA, Kouzekanani K, Hanis CL. The Starr county diabetes education study: Development of the
Spanish-language diabetes knowledge questionnaire. Diabetes Care 2001;24(1):16-21

13. Pongmesa T, Li SC, Wee HL. A survey of knowledge on diabetes in the central region of Thailand. Value Health 2009;12:S110-3.

14. Qamar M, Lau WH, Ahmed A, Ahmed F, Khan J, Mahmud A. Knowledge of diabetes mellitus, risk factors and complications among the general public in Kuala Lumpur. World J Pharm Res 2015;4:1-18.

15. Sagaran R, Srinivasan N. Public awareness of diabetes mellitus in Klang district, Selangor. Int J Allied Med Sci Clin Res 2014;2:186-95.

16. Mohd MN, Dali AF, Ahmad A, Sulaiman S, Hussin SN, N'Ainun M. Knowledge and attitude on diabetes among public in Kota Bharu. Int $\mathrm{J}$ Educ Res 2014;2:1-10.

17. Institute for Public Health (IPH). National Health and Morbidity Survey (NHMS. 2015). Vol. II. Non-Communicable Diseases, Risk Factors and Other Health Problems; 2015.

18. Arafat M, Salam A, Arafat O. The association of Type 2 diabetes with obesity and other factors: In multinational community. Int J Pharm Pharm Sci 2014;6:257-60. Available from: http://www.innovareacademics.in/ journals/index.php/ijpps/article/view/2179/1230.

19. Moradi M, Mousavi S. Drug use evaluation of diabetes mellitus in nonhospitalized patients. Int J Pharm Pharm Sci 2016;8:337-41. Available from: http://www.innovareacademics.in/journals/index.php/ijpps/ article/view/12858.

20. Khalam A, Dilip C, Shinu C. Drug use evaluation of diabetes mellitus in hospitalized patients of a tertiary care referral hospital. J Basic Clin Physiol Pharmacol 2012;23(4):173-7.

21. Van den Brink G, Schwartzenberg RR, Hoeve LJ, Porsius AJ, Hoeve LL. The use of hypoglycaemic and cardiovascular drugs in 582 patients with diabetes mellitus. Description and quality assessment. Pharm World Sci 1993;15(3):128-31.

22. Wee HL, Ho HK, Li SC. Public awareness of diabetes mellitus in Singapore. Singapore Med J 2002;43(3):128-34.

23. Mohieldein AA, Alzohairy M, Hasan M. Awareness of diabetes mellitus among Saudi non-diabetic population in Al-Qassim region, Saudi Arabia. J Diabetes Endocrinol 2011;2:14-9. Available from: http:// www.174.142.63.240/article/article1379411353_Mohieldeinetal.pdf.

24. Ding CH, Teng CL, Koh CN. Knowledge of diabetes mellitus among diabetic and non-diabetic patients in Klinik Kesihatan Seremban. Med J Malays 2006;61:399-404

25. Ahmad S, Srivastava A, Bansal R, Parashar P, Pant B. Knowledge and awareness regarding diabetes mellitus in slum of Meerut. Indian J Community Health 2013;25:12-5.

26. Murata GH, Shah JH, Adam KD, Wendel CS, Bokhari SU, Solvas PA, et al. Factors affecting diabetes knowledge in Type 2 diabetic veterans. Diabetologia 2003;46(8):1170-8.

27. Rahman ZU, Irshad M, Khan I, Abbas HU. A survey of awareness regarding diabetes and its management among patients with diabetes in Peshawar, Pakistan. J Postgrad Med Inst 2014;28:372-7.

28. Soltanian AR, Bahreini F, Afkhami-Ardekani M. People awareness about diabetes disease and its complications among aged 18 years and older in Bushehr port inhabitants (Iran). Diabet Metab Syndr Clin Res Rev 2007;1:245-9.

29. Berhe KK, Gebru HB, Kahsay HB, Kahsay AA. Diabetes and metabolism assessment of diabetes knowledge and its associated factors among Type 2 diabetic patients in Mekelle and Ayder referral hospitals, Ethiopia. J Diabet Metab Disord 2014;5:7-9.

30. Binh T, Phuong P, Nhung B. Knowledge and associated factors towards Type 2 diabetes among a rural population in the red river delta region, Vietnam. Int Electron J Rural Remote Health Res Educ Pract Policy 2015;15:3275

31. Gonzalez HM, Vega WA, Rodrigue MA, Tarraf M, Sribney WM. Diabetes awareness and knowledge among latinos: Does a usual source of healthcare matter? J Gen Intern Med 2009;24:528-33.

32. Jasper US, Ogundunmade BG, Opara MC, Akinrolie O, Pyiki EB, Umar A. Determinants of diabetes knowledge in a cohort of Nigerian diabetics. J Diabet Metab Disord 2014;13:1-8.

33. Strauss SM, Singh G, Tuthill J, Brodsky A, Rosedale M, Bytyci A, et al. Diabetes-related knowledge and sources of information among periodontal patients: Is there a role for dental hygienists? J Dent Hyg 2014;87:82-9. 